\title{
Introduction to the Forum on COVID-19
}

\author{
Juan Luis Manfredi Sánchez | oooo-0oo1-9129-2907 \\ Journalism \& International Studies, University of Castilla-La Mancha, \\ Cuenca, Spain \\ Juan.manfredi@uclm.es
}

Six months have passed. Only six months, and we already know that yesterday's world has vanished with more than 27 million people infected, and about 1 million dead from CoviD-19. The transformation of politics and international relations has accelerated, and the trends that had previously been identified seem to be undergoing consolidation. We can point to some milestones along the way, such as the decline of the multilateral system, the weak position of the European Union, the disinterest of Trumpism in liberal ideals, the rise of China, economic deglobalisation, inequality, the gender perspective and the digital transformation. None of these issues is so new that it merits the term pandemic diplomacy with regard to the academic study and practice of diplomatic endeavours, yet it represents a starting point for in-depth analysis of the consequences of such issues on the international system and the diplomatic profession.

In general, diplomacy will have to adapt to a world divided among different strategic options. The struggle to develop a vaccine is a contest to see who will spearhead the success story and take on international leadership, as well as substantial economic benefits. China, the United States, the United Kingdom, the European Union and even Russia are all undertaking projects with mixed results. The World Health Organization (WHO) has been the first victim of the problems of multilateralism in the face of growing anti-diplomatic forces. Regulatory power has been ruled out, while operational capacity is being blocked by economic cutbacks. The national approach among nations has undermined the actual authority of the wHO and remains a symbol of desired cooperation rather than an organisation endowed with diplomatic management. Benefits could be achieved if diplomatic activity contributed to changing this dynamic and allowed for the promotion of best practice along with implicit consensus to act outside the realm of momentary political decisions. Thus, 
the concept of human diplomacy is the interconnection of solutions aimed at global co-operation to reduce the uncertainty of the pandemic and other transformations that are still to come.

In terms of actors, the pandemic has revealed the value of networks in dealing with crises. Small countries, cities and non-governmental organisations can provide distinctive value in building an environment of trust and efficiently carrying out campaigns for the prevention, surveillance and monitoring of COVID-19. Without these actors, the state would be unable to implement its own response. The role of public-private partnerships in the implementation of projects (hospitals, transportation and biomedical research), or the impact of artificial intelligence on forecasts and data analysis should be included in the future research agenda. Transport infrastructures of logistics companies and opinion-makers are now key influencers of diplomatic success. The lack of vision in the first months of the crisis, together with insufficient collaboration, has devastated the international economy, undermined confidence and weakened the multilateral system. The diplomacy still to come will need to be receptive to these new players, even if nation states continue to pursue a command and control strategy.

The diplomatic profession has confirmed the winds of change in the relationship between political power and diplomatic activity. The agenda now offers more diversity of approaches, work methods and the recruitment of talent. At the present time, diplomats are not, nor will they be, military units fragmented into specialisations (infantry, artillery or navy) but rather they are professionals of dialogue, information, negotiation and the defence of national interests, whatever their destiny may be. Attention will have to be paid to the way in which negotiations are conducted in virtual summits without personal proximity or small huddles of people. The task of Sherpa senior diplomats who assist political leaders in achieving foreign policy goals is becoming increasingly important. The management of COVID-19 should offer lessons for cybersecurity, climate change and migration. Diplomacy cannot remain a mere act of observation. Instead, its power to influence must be increased, as for example in the opening of borders or the global distribution of a vaccine. Perhaps lessons can be learned from the Antarctic experience in carrying out this task.

The pandemic has caused a paradox, or paradoxical situation. In an age of social networks and disinformation, slow diplomacy that is more suited to consular work and discreet negotiations is required to meet the needs of citizens wherever privations might arise in situations of closed borders and artificial barriers to the free movement of people. However, the pandemic has revealed the shortcomings of the international information disorder. Without reliable sources, propaganda circulates at great speed from screen to screen - in 
dubio, pro dubio. Ministries, chancelleries and diplomats will have to assert themselves as a standard for validating international information with the aim of creating public value.

In short, the coming diplomacy will have to adapt to an international order of which we have little knowledge. For the actors involved, now is the time to recognise the value of the internet when facing the established hierarchy. For the professional diplomat, this is the time to learn: the next crisis will be the same, yet distinct. We must try to avoid the error of 'fighting the last war'. Finally, as academics, we will have to renew our knowledge and research agenda, promote ongoing education and develop new doctrines. The times ahead, whether confined or not, will undoubtedly be exciting.

\section{Juan Luis Manfredi Sánchez}

is a Senior Lecturer at the University of Castilla-La Mancha, where he teaches International Studies and Journalism. He leads the research group 'Public Communication: Power, Message, and Law', devoted to analysing European media policies, international communication and free speech. Currently, his group is comparing global city diplomacy in Europe and Latin America. 